Mercedes López Rodríguez BLANCURA Y OTRAS FICCIONES RACIALES
EN LOS ANDES COLOMBIANOS
DEL SIGLO XIX

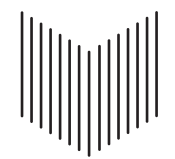




\section{JUEGO DE DADOS}

Latinoamérica y su Cultura en el XIX

\section{8}

De acuerdo con las palabras de Alfonso Reyes en su ensayo "Última Tule", igual que ocurre en el juego de dados de los niños "cuando cada dado esté en su sitio tendremos la verdadera imagen de América”.

\section{CONSEJO EDITORIAL}

WILLIAM ACREE

Washington University in St. Louis

CHRISTOPHER CONWAY

University of Texas at Arlington

PURA FERNÁNDEZ

Centro de Ciencias Humanas y Sociales, CSIC, Madrid

BEATRIZ GONZÁLEZ-STEPHAN

Rice University, Houston

FRANCINE MASIELLO

University of California, Berkeley

ALEJANDRO MEJÍAS-LÓPEZ

University of Indiana, Bloomington

GRACIELA MONTALDO

Columbia University, New York

ANDREA PAGNI

Friedrich-Alexander-Universität Erlangen-Nürnberg

ANA PELUFFO

University of California, Davis 
Mercedes López Rodríguez

\section{BLANCURA Y OTRAS FICCIONES RACIALES EN LOS ANDES COLOMBIANOS DEL SIGLO XIX}




\section{Derechos reservados}

(C) Iberoamericana, 2019

Amor de Dios, 1 - E-28014 Madrid

Tel.: +34914293522

Fax: +34914295397

(C) Vervuert, 2019

Elisabethenstr. 3-9 - D-60594 Frankfurt am Main

Tel.: +49695974617

Fax: +49695978743

info@iberoamericanalibros.com

www.ibero-americana.net

ISBN 978-84-8489-642-5 (Iberoamericana)

ISBN 978-3-95487-762-1 (Vervuert)

ISBN 978-3-95487-763-8 (e-book)

Depósito Legal: M-28308-2019

Impreso en España

Diseño de cubierta: Marcela López Parada

Ilustración de cubierta: Carmelo Fernández, Ocaña. Mujeres blancas. Colección Biblioteca Nacional de Colombia (1852).

Este libro está impreso íntegramente en papel ecológico sin cloro. 

Para Nicholas, porque uno de los placeres de escribir libros es poder dedicárselos.

Para los campesinos colombianos y su lucha por un mundo mejor y más justo.

Para todos mis mentores, presentes y pasados, por su inspiración y afecto. 
